\title{
Modeling of fragmentation in the Construction Industry
}

\author{
Min Wu \\ Department of Real Estate and Construction \\ University of Hong Kong \\ Hong Kong, PR China \\ minwu@hku.hk
}

\begin{abstract}
This study develops a self recruitingsubletting cost indifference point model to explain the fragmentation in the structure of the construction industry. Although a high proportion of small firms in the construction industry has be criticized as it prevents the exploitation of economies of scale, the self recruiting-subletting cost indifference point model theoretically proposes that subletting is usually profitable for construction firms; thus the size distribution of the construction industry should skewed towards small firms.
\end{abstract}

Key words: Construction, industry structure, self recruiting, subletting cost indifference point

\section{INTRODUCTION}

The construction industry is usually smaller than that in the manufacturing industry [1-4]. Pearce [4] feels that the basic structure of the construction industry, namely, the preponderance of small companies, precludes the exploitation of economies of scale and hence poses special problems for cost reductions and adding value. The model developed in this paper suggests that the size distribution of the construction industry must skew towards small firms. This paper consists of three parts. Following the introduction, Section II develops a self recruiting-subletting cost indifference point model for a firm to decide whether it should sublet a workload to a sub-contractor. Section III discusses the model. Section IV presents an example to demonstrate how the model can be applied to the construction industry. Section V concludes the study.

\section{THE MODEL}

The construction industry is dominated by small firms. This has mainly resulted from subletting practices. This section aims to develop a model to help a firm to decide whether it should sublet workload to a sub-contractor.
A factory produces a manufacturing product, such as a desktop computer. A contractor builds a construction product, for example a hotel. Either the manufacture of a desktop computer or the construction of a hotel involves many trades. A computer consists of a monitor, keyboard, hard disc, motherboard, floppy disk drive, DVD drive, speaker, case, power supply, etc. The manufacture of the power supply can be further broken down to wiring, welding, etc. The construction of a hotel involves substructure, superstructure, finishing, fittings, services, etc. The services can be further broken down to plant, pipe installation, electrical wiring, etc. To complete an approved task, for example, welding, a firm (which could be a manufacturer or a contractor) can purchase its own facilities and hire its own employees to complete the task, or alternatively, can sublet the workload to a subcontractor.

To recruit its own people, the firm needs to pay a recruiting fee, $k(\$)$. The recruiting expenditure includes an advertisement fee, interview expenditure, or the fee paid to an employment agency. The recruiting fee is assumed to be fixed for each round, no matter how many people are recruited. The number of people recruited in each round is $Q$. The annual salary is $P_{\text {self }}(\$)$. The firm also needs to set up a workshop and purchase its own facilities, such as welding machines, fire extinguishers, etc. The facilities are usually in proportion to the number people using the facility. To cut down its expenditure, when a task is completed, the firm releases its workforce again. The firm recruits new people when a new task arises. The sum of the workload of the tasks is $D$ (man.year/annum). Although people may be released when a task is complete, the firm has to keep all the facilities for the next task. The annual cost of keeping the facilities and 
workshop per person is $H(\$)$. Alternatively, the firm may sublet its work to a sub-contractor. In such a case, all the recruiting fees and facility fees are transferred to the sub-contractor, but charged back to the firm as a higher unit cost per annum $P_{\text {sublet }}(\$)$ (i.e., $P_{\text {sublet }}$ is greater than $\left.P_{\text {self }}\right)$. This study assumes that $k, Q, P_{\text {self }}$, $D, H$ and $P_{\text {sublet }}$ are constant and $D$ is predictable.

Previous studies (Wu, 2004; $\mathrm{Wu}$ and Low, 2005a, b) suggest that the crux for the decision whether a firm should hire its own employees to complete tasks or sublet the workload to a sub-contractor is to uncover the cost indifference point between the self recruiting system and the subletting system. The self recruiting-subletting cost indifference point is the amount of workload at which the total annual optimum cost under a self recruiting system equals the total annual cost under a subletting system. Based on the conditions above, the total cost under the self recruiting system, $T C_{\text {self }}$ is the sum of the recruiting costs, holding costs, and the salaries paid directly to employees, or:

$$
T C_{\text {self }}=\frac{k D}{Q}+H Q+P_{\text {self }} D
$$

The optimal number of people recruited in each round which can minimize the total cost under the self recruiting system, $Q^{*}$ can be found by taking the first order derivative with respect to $Q$ of Eq. 1 and setting it to equal to zero, and is:

$Q^{*}=\sqrt{\frac{k D}{H}}$

Eq. 2 results in a total annual optimal cost under the self recruiting system as:

$$
T C_{\text {self }}=2 \sqrt{k D H}+P_{\text {self }} D
$$

As suggested earlier, under the subletting system, the recruiting cost and holding cost are mainly transferred to the sub-contractor. The total annual cost under the subletting system, $T C_{\text {sublet }}$, thus is the product of $P_{\text {sublet }}$ and $D$, given by:

$T C_{\text {sublet }}=P_{\text {sublet }} D$

$P_{\text {sublet }}$ is greater than $P_{\text {self }}$ to partially reflect the facility cost and recruiting costs that have been transferred to the sub-contractor.
To make a comparison between the total costs under the self recruiting system and that under the subletting system, a $Z$ model that combines the total annual optimal cost under the self recruiting system in Eq. 3 and the total annual cost under the subletting system in Eq. 4 can be presented as:

$Z=2 \sqrt{k D H}+P_{\text {self }} D-P_{\text {sublet }} D$

$Z$ represents the cost difference between a self recruiting system and a subletting system. $Z$ is continuous and differentiable as the workload, $D$ is greater than or equal to zero. Taking the first order derivative of $Z$ with respect to $D$ in Eq. 5, will result in:

$$
\frac{d Z}{d D}=\sqrt{k H}\left(D^{-1 / 2}\right)+P_{\text {self }}-P_{\text {sublet }}
$$

Taking the second order derivative of $Z$ with respect to $D$ in Eq. 5, will result in:

$$
\frac{d^{2} Z}{d D^{2}}=\frac{-\sqrt{k H}}{2} D^{-3 / 2}
$$

Note that $\frac{\sqrt{k H}}{2}$ is always positive. $D^{-3 / 2}$ is always positive, as $D$ is above zero. Hence, $\frac{d^{2} Z}{d D^{2}}$, the second order derivative of $Z$ with respect to $D$ is always negative. Therefore, the curve of $Z$ is concave downwards. Setting $D$ (the workload) to be zero, will result in:

$$
Z_{0}=0
$$

where $Z_{0}$ is the cost difference between the self recruiting system and the subletting system when the workload equals zero. Since $Z_{0}$ equals zero and the curve of $Z$ is concave downwards, there must exist a break-even point at which $Z$ equals zero. Setting $Z$ equal to zero, the root of Eq. 5 is the self recruiting-subletting cost indifference point, $D_{\text {indr }}$ :

$$
D_{\text {indr }}=\frac{4 k H}{\left(P_{\text {sublet }}-P_{\text {self }}\right)^{2}}
$$

\section{DISCUSSION}

The self recruiting-subletting cost indifference point model is developed from the economic order quantity (EOQ) and just-in-time (JIT) material purchasing models developed by Harris (1915), Fazel (1997), Fazel et al. (1998), Schniederjans and Olsen (1999), Schniederjans and Cao $(2000,2001), \mathrm{Wu}(2004)$, and $\mathrm{Wu}$ and Low (2005 a, b). Whilst the EOQ-JIT cost indifference models examines the material 
purchasing approaches, the self recruitingsubletting cost indifference point model focuses on personnel recruiting. The self recruiting- subletting cost indifference point is shown in Figure 4.

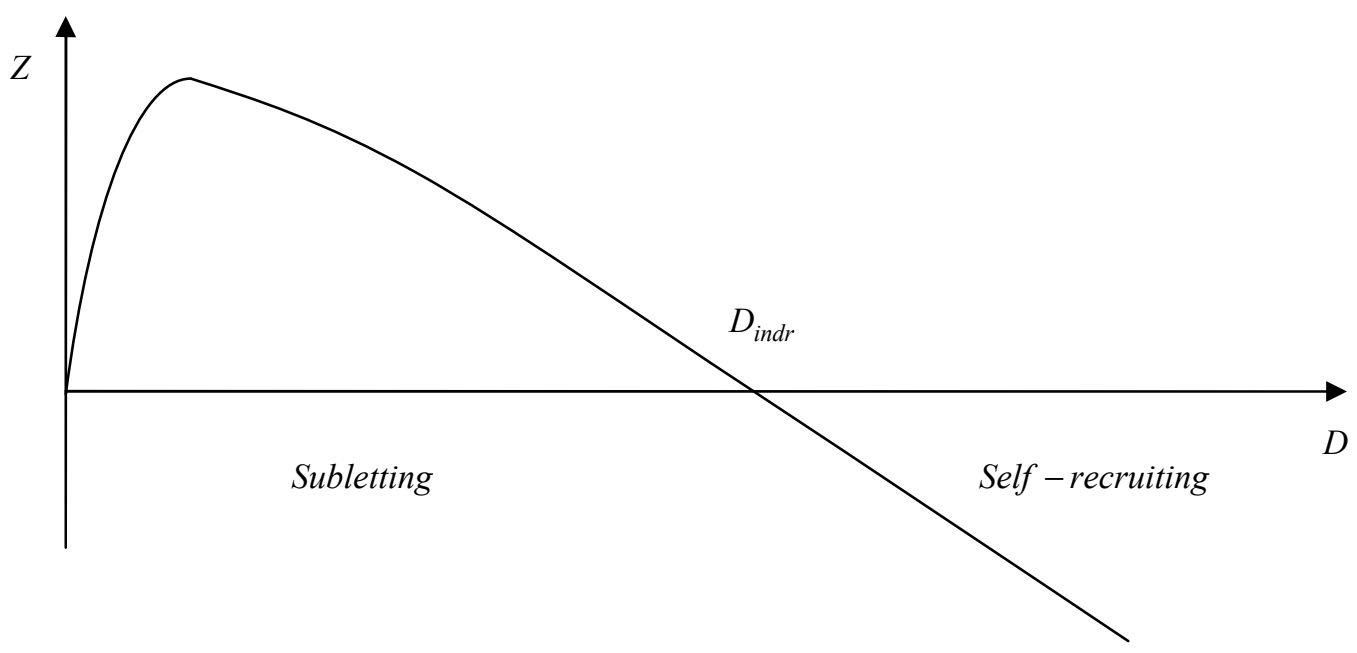

Figure 4 The self recruiting-subletting cost indifference point

Two rules can be summarized from Figure 4 . Rule 1 is that when the self recruiting-subletting cost indifference point $D_{\text {indr }}$ is a constant, a firm with a low workload may sublet its workload to a sub-contractor and a firm with a high workload probably should purchase its own facility and recruit its own people to finish a task. Rule 2 is that when workload is a constant, shifting the self recruiting-subletting cost indifference point $D_{\text {indr }}$ (see Eq. 9) to a higher value encourages subletting the workload to a sub-contractor.

Figure 4 seems to suggest that whilst a selfrecruiting system should be encouraged in the manufacturing industry, subletting is probably a more economically viable alterative in the construction industry. The construction industry is project-oriented. The contractor has to shift to a new construction site for a new project. The frequent shifting incurs additional costs for maintaining facilities thus increasing $H$ in the self recruiting-subletting cost indifference point model in Eq. 9, therefore shifting $D_{i n d r}$ to a higher value, forcing construction firms to skew towards a subletting system, even when workload remains constant. This is Rule 2.

The workload for a specific kind of person (much as a welder) for a project is usually low.
The reasons are two-fold. First, "one-off" designs are normal in the construction industry, as the final product of construction is usually of unique composition and is site specific (Low and Chan, 1997). Hence, there is seldom a "standard" process in the construction industry. Second, the construction industry is highly fragmented with different transient project consultants, builders and suppliers. Since the workload for a specific kind of tradesperson for a construction project is low, based on Rule 1, subletting is again probably a more economic viable alternative for a contractor.

The workload for each kind of tradesperson in the manufacturing industry is usually high, as the situation in the manufacturing industry is conversely different from that in the construction industry. In the manufacturing industry, standard designs and repetitive processes are strictly adhered to. The standard designs and repetitive production runs are usually adopted for a specific period of time until the next change in design arises, usually a few years later to accommodate changes in marketing strategies (Low and Chan, 1997). According to Rule 1, and since it is possible for the workload for a specific kind of tradesperson in the manufacturing industry to be higher than the self recruiting-subletting cost indifference point, a self recruiting system should be encouraged in the manufacturing industry. 
In summary, the self recruiting-subletting cost indifference point model suggests that the construction industry should encourage subletting and the industry should skew towards small firms. This is what the data shows. The self recruiting-subletting cost indifference point is further illustrated by means of an example.

\section{AN EXAMPLE}

An underground liquefied petroleum gas (LPG) terminal project is under construction. The project has two caverns with a total storage capacity of 200,000 tonnes of LPG. The total investment of the project is US\$ 100 million. Company $\mathrm{A}$ is the client and Company $\mathrm{B}$ is the main contractor. Company $\mathrm{A}$ is considering whether it should hire two quality insurance engineers for checking the piping welding jobs. Annual salary for recruiting a quality insurance engineering is $P_{\text {self }}=\mathrm{US} \$ 12,000$. The annual cost of keeping the facilities and providing professional training per quality insurance engineer is about $H=\mathrm{US} \$ 20,000$, as the facilities for LPG piping welding checks are quite expensive. The recruiting process cost is $k=\mathrm{US} \$ 3,000 /$ round. If the workload is sublet to a specialist firm, the annual salary quoted by the specialist firm for a quality insurance engineer is $P_{\text {sublet }}=\mathrm{US} \$ 17,000$. According to Eq. 9, the self recruiting-subletting cost indifference point, $D_{\text {indr }}=10 \quad$ (man.year/annum). Hence, the workload for the piping welding quality check $D$, which is 2 (man.year/annum), is smaller than $D_{\text {indr }}$. Therefore, Company A should sublet its piping quality check workload to the specialist firm. Indeed, as observed by RCBCI (2002a) and CFR (2003), the majority of the construction works in the UK and Australian construction industries were sublet to small specialist firms. Such practice is beneficial for both the contractors and the sub-contractors.

\section{CONCLUSIONS}

The construction industry is heavily skewed towards small firms. This study develops a self recruiting-subletting cost indifference model to assist a firm to decide whether it should recruit its own employee to complete a task or sublet the workload to a sub-contractor. Whilst the overwhelming number of small firms can be criticized as it prevents the exploitation of economies of scale; the self recruiting-subletting cost indifference model suggests that subletting is probably a profitable practice for construction firms. As such, the size distribution of the construction industry should skew toward small firms.

\section{REFERENCES}

[1] Ofori, G. (1990). The Construction Industry: Aspects of Its Economics and Management, Singapore University Press.

[2] CFR (2003). A Review of the Size and Structure of the UK Construction Industry, Report to Ncrisp, Construction Forecasting and Research, nCRISP, London

[3] RCBCI (2002). Discussion paper 1: Overview of the natural and operation of the building and construction industry, Royal Commission into the Building and Construction Industry, retrieved in May 2005, http://www.royalcombci.gov.au.

[4] Pearce, D. (2003). The Social and Economic Value of Construction The Construction Industry's Contribution to Sustainable Development, The Construction Industry Research and Innovation Strategy Panel.

[5] Wu, M. and Low, S. P. (2007), "Modelling Just-in-time purchasing in the ready mixed-concrete industry", International Journal of Production Economics, (Publisher: Amsterdam: Elsevier) (SCI \& EI journal), 107(1), pp.190-201. 